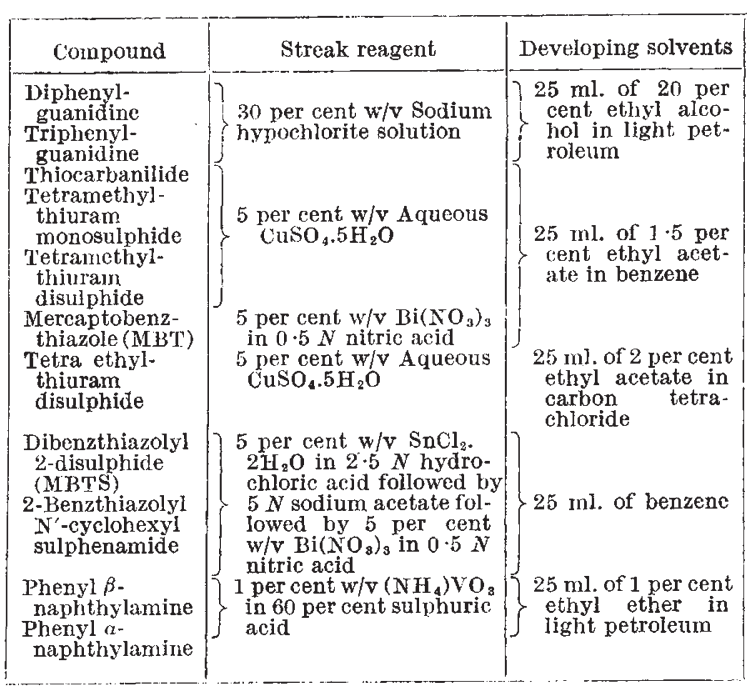

ably unambiguous identification, which can be further confirmed by ultra-violet absorption measurements.

Using this method, it is possible to distinguish between the compounds named in the table even when present in admixture with one another and with other normal compounding ingredients, including pine tar. In most cases quantities as small as $0.05 \mathrm{mgm}$. can be detected on a column of $1 \mathrm{~cm}$. diameter.

The same developers can be used for the detection of other accelerators and anti-oxidants, although complete separation from all other compounds cannot always be attained with a single chromatographic treatment. Thus it has been possible to detect $m$-toluylene diamine, sym-diphenyl-p-phenylene diamine, sym-dinaphthyl- $p$-phenylene diamine and some complex commercial materials containing, for example, aldehyde-amine condensation products or polymerized dihydroquinoline derivatives. The separation of more elosely related compounds can also be attained. For example, derivatives of dimethyl-, diethyl- and dibutyl-dithiocarbamates can readily be distinguished from one another by chromatographing the brown copper complexes.

With minor modification, some of the methods can be adapted for quantitative determination. Good recovery of adsorbates has been obtained with the particular silica gel adsorbent in use. In this connexion, Bloomfield ${ }^{5}$ has suggested that alumina may cause decomposition of labile accelerators during chromatography, and that such products may be mistaken for transformation products of the accelerator produced during the vulcanization process. Mann ${ }^{2}$ has, in fact, observed the decomposition of dibenzthiazolyl 2-disulphide to mercaptobenzthiazole on alumina columns. In contrast, I have found that dibenzthiazolyl 2-disulphide can be chromatographed unchanged on our silica gel columns. Nevertheless, I have identified both mercaptobenzthiazole and dibenzthiazolyl 2-disulphide in the extracts of rubbers accelerated with either; this is in agreement with the findings of Dufraisse and Houpillart ${ }^{6}$. I have also observed mercaptobenzthiazole in the extract of a rubber accelerated with 2-benzthiazolyl $\mathrm{N}$-cyclohexyl sulphenamide. However, considerable care is required in the interpretation of the chromatograms, as there is evidence that labile accelerators can undergo further transformation during the process of acetone extraction of the rubber.
This investigation is continuing and will bo reported in detail elsewhere.

Admiralty Materials Laboratory,

C. A. Parker

Holton Heath, Poole, Dorset. Feb. 14.

${ }^{1}$ Bellamy, L. J., Lawrie, J. H., and Press, E. W. S., Trans. Inst. Rubber Indust., 22, 308 (1947); 23, 15 (1947).

${ }^{2}$ Mann, J., Trans. Inst. Rubber Indust., 27, 232 (1951).

${ }^{3}$ Ovenston, T. C. J., J. Soc. Chem. Indust., 68, 54 (1949) ; Analyst, 74, 344 (1949).

4 Parker, C. A., J. Soc. Chem. Indust., 67, 434 (1948)

${ }^{5}$ Bloomfield, G. F., Trans. Inst. Rubber Indust, 23, 172 (1947).

${ }^{-}$Dufraisse, C., and Houpillart, J., Rev. gén. caoutchou, 19, 207 (1942).

\section{Translocation of Iron in Podzol Formation}

Several mechanisms have been postulated to account for the translocation of iron and aluminium in the process of podzol formation. Thus Jones and Willco ${ }^{1}$ suggest that simple organic acids such as oxalic acid are responsible for the solution of the sesquioxides, while numerous workers ${ }^{2}$ consider that the free oxides are peptized by tho action of humus and move as sols.

It has been found in this laboratory that water extracts of the undecomposed leaves and bark of the New Zealand kauri (Agathis australis) and of Scots pine needles (Pinus sylvestris) are capable of causing rapid reduction of soluble ferric compounds to the extent of some $4-5 \mathrm{mgm}$. of iron per gram of air-dry Scots pine necdles. Furthermore, over a wide range of $p \mathrm{H}$ values (4-7), the extracts are capable of causing non-biological solution of relatively large amounts of hydrous ferric and aluminium oxides. Ferrous iron, as determined by $\alpha \alpha^{\prime}$-dipyridyl, accounts only for a part of the dissolved iron; but as the extracts are still capable of reducing considerably more iron than has already been dissolved, it is unlikely that the difference between the total and the dipyridyl-reactive iron represents iron in the ferric state. Experiments on the effect of the plant extracts on the recovery of ferrous iron by dipyridyl from solutions of ferrous sulphate show that complexing of the ferrous iron is, in part at least, the cause of the discrepancy between the total and the dipyridylreactive iron. It therefore seems probable that the whole of the dissolved ferric oxide is reduced to the ferrous state. Continuous aeration of the reaction mixture appears to have little or no effect on the solution and reduction of ferric oxide. These results resemble very closely those previously obtained with anaerobically fermented grass ${ }^{3}$.

It can be seen from these results that the percolation of rainwater through undecomposed coniferous litter provides all the necessary conditions for the leaching of sesquioxides from the surface layers of the soil. In view of the capacity of the aqueous extracts for reducing ferric iron, it seems most probable that translocation of the iron takes place in the form of a ferrous organic complex.

Pedology Department,

C. BLOOMfeidn

Rothamsted Experimental Station, Harpenden, Herts. March 10.

${ }^{1}$ Jones, II. T., and Willcox, J. S., J. Soc. Chem. Indust., 48T, 304 (1929).

2 Morison, C. G. T., and Sothers, D. B., J. Agric. Sci., 6, 84 (1914). Aarnio, B., Pochvovednie, 17, (2), 1 (1915). Mattson, S., Soil

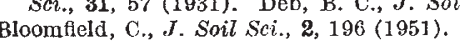

